\title{
PENGARUH PELATIHAN KETERAMPILAN BELAJAR MANDIRI TERHADAP MOTIVASI BELAJAR MAHASISWA PADA PENDIDIKAN JARAK JAUH
}

\author{
Anfas \\ Universitas Terbuka \\ e-mail: anfas_st_mm@ecampus.ut.ac.id
}

\begin{abstract}
This study aims to determine the effect of the Independent Learning Skills Training on student motivation in distance learning systems at UPBJJ-UT Ternate. The research sample was new Bidikmisi scholarship students in UPBJJ-UT 2019.2 registration period, namely 20 students. The results of the regression analysis produce the equation $Y=$ $a+b X=5.274+1.337 X$. This means that each increase in the quality of Independent Skills Training by 1 unit will increase Student Learning Motivation by 1,337. The coefficient of determination ( $R$ Square) of 0.712 explains that the contribution of the influence of the PKBM variable $(X)$ to the Learning Motivation variable $(Y)$ is $71.20 \%$. While the remaining $28.80 \%$ is influenced by other variables not examined. Based on these results, the researcher proposes that UT should continue to be able to improve PKBM standards to be better so that it helps new UT students in their learning process.
\end{abstract}

Keywords: training, skills, independent, motivation.

Abstrak: Penelitian ini bertujuan untuk mengetahui pengaruh Pelatihan Keterampilan Belajar Mandiri (PKBM) terhadap motivasi belajar mahasiswa pada sistem belajar jarak jauh di UPBJJ-UT Ternate. Populasi penelitian adalah mahasiswa baru UPBJJ-UT Ternate yang menerima beasiswa Bidikmisi di masa registrasi 2019.2 sebanyak 20 mahasiswa. Dimana seluruh populasi dijadikan sebagai sampel penelitian. Dari hasil analisis regresi menghasilkan persamaan $Y=a+b X=5.274+1.337 X$. Artinya bahwa setiap peningkatan kualitas Pelatihan Keterampilan Mandiri sebesar 1 satuan, maka akan meningkatkan Motivasi Belajar Mahasiswa sebesar 1,337 satuan. Hasil koefisien determinasi R2 (R Square) sebesar 0,712 menjelaskan bahwa presentase sumbangan pengaruh variabel PKBM $(X)$ terhadap variabel Motivasi Belajar $(Y)$ sebesar $71,20 \%$. Sedangkan sisanya $28,80 \%$ dipengaruhi atau dijelaskan oleh variabel lain yang tidak dimasukkan dalam model penelitian ini. Berdasarkan hasil penelitian ini, maka peneliti mengusulkan agar UT harus terus dapat meningkatkan standar PKBM sehingga semakin baik dan dapat membantu mahasiswa baru UT dalam menjalani proses belajarnya.

Kata kunci: pelatihan, keterampilan, mandiri, motivasi.

\section{PENDAHULUAN}

Sistem pendidikan jarak jauh telah diperkenalkan sejak abad ke-19. Dimana pertama kali dikembangkan di Jerman, Inggris dan Amerika, yakni melalui penyelenggaraan kursus jarak jauh yang dilakukan secara korespondensial. Kursus-kursus tersebut dimaksudkan untuk memberikan pelatihan kejuruan untuk melayani tuntutan pertumbuhan ekonomi industri, sehingga menjadi popular dan semakin diminati oleh masyarakat luas (Neal, 1999). 
Di tiap negera, penyelenggaraan pendidikan jarak jauh memiliki tujuan yang berbeda-beda. Di negara-negera maju, pendidikan jarak jauh diselenggarakan untuk melayani individu-individu yang membutuhkan layanan pendidikan untuk mengembangkan potensi dirinya. Sementara di negera-negara berkembang, pendidikan jarak jauh ditujukan untuk melayani masyarakat secara masal agar memperoleh kesempatan pendidikan bagi masyarakat luas. Terutama dalam meningkatkan angka partisipasi kasar perguruan tinggi Negara tersebut (Ural, 2007).

Seiring perkembangan zaman, dimana teknologi semakin canggih, maka pengembangan layanan sistem pendidikan jarak jauh semakin beragam. Universitas penyelenggara pendidikan jarak jauh di berbagai negara pun semakin tumbuh berkembang, dengan fasilitas layanan pendidikan yang semakin variatif, seperti menggunakan media elektronik, cetak dan internet (Neal. 1999). Dengan adanya beragam fasilitas layanan pendidikan tersebut, telah mengubah paradigma pendidikan jarak jauh yang awalnya hanya bersifat monoton, kini lebih variatif. Jika dulu presentasi materi ajar hanya disajikan dalam bentuk tercetak, terekam, maupun tersiar, sehingga cenderung komunikasi hanya bersifat satu arah, dari dosen kepada mahasiswanya. Maka kini, dengan kemajuan teknologi informasi (TI) telah memungkinkan komunikasi dua arah antara dosen dan mahasiswa (Belawati, 2002).

Namun, terlepas dari perkembangan berbagai fasilitas layanan pendidikan tersebut, yang paling utama menjadi kunci keberhasilan pendidikan jarak jauh adalah bagaimana menumbuhkan kemandirian mahasiswanya. Salah satu kendala dalam pembelajaran jarak jauh adalah menumbuhkan kesadaran mahasiswanya untuk mampu belajar secara mandiri dan konsisten memelihara motivasi belajarnya. Hal ini dikarenakan dalam sistem belajar jarak jauh proses belajar mahasiswa tidak bertatap muka secara langsung dengan dosen melainkan melalui berbagai media yang menjadi perantara (Universitas Terbuka, 2012).

Ketidaksiapan peserta didik melaksanakan belajar mandiri pada pendidikan jarak jauh, telah menyebabkan tingkat putus kuliah (retensi) sangat tinggi jika dibandingkan dengan perguruan tinggi tatap muka (Bolliger dan Martindale, 2004). Bahkan Moore dan Kearsley (1996), mengemukakan bahwa tingkat retensi mahasiswa pada pendidikan jarak jauh dapat mencapai $30 \%-50 \%$.

Telah banyak penelitian yang dilakukan untuk mengetahui pengaruh kemandirian belajar terhadap prestasi belajar mahasiswa di Universitas Terbuka (UT). Penelitian Dedi S. dkk (2016), Sylvana dan Alwi (2016), dan Prayekti dkk (2016) menunjukkan hasil bahwa terdapat pengaruh signifikan antara kemandirian belajar terhadap prestasi belajar mahasiswa UT.

Kemandirian belajar tentunya bukan merupakan bakat atau bawaan yang dibawa sejak lahir, sehingga harus ditumbuhkan dan dikembangkan dalam proses pendidikan (Aisyiyah, 2013). Untuk itu peran lembaga pendidikan sangat penting. Sehingga mulai tahun 2018, UT telah menyelenggarakan Pelatihan Keterampilan Belajar Mandiri (PKBM) bagi mahasiswa baru. Kegiatan PKBM secara berkelanjutan diselenggarakan oleh UT dalam upaya meningkatkan prestasti belajar mahasiswanya. 
Menurut Hasibuan (2005), pelatihan adalah bagian dari pendidikan yang menyangkut proses belajar untuk mendorong dan meningkatkan keterampilan di luar sistem pendidikan yang berlaku dalam waktu dan teori yang relatif singkat dengan metode yang mengutamakan praktek daripada teori. Dalam PKBM mahasiswa diperkenalkan dengan konsep tentang sistem belajar jarak jauh, berlatih belajar cerdas (membaca cepat dan strategi merangkum hasil bacaan) serta praktek untuk mengakses layanan bantuan belajar secara online, mulai dari tutorial online, bahan ajar digital, perpustakaan online, materi web-suplemen, latihan mandiri online dan lainnya yang memiliki kaitan dengan proses belajar di UT (Universitas Terbuka, 2018). Melalui pelatihan tersebut diharapkan mampu meningkatkan motivasi mahasiswa dalam belajar.

Menurut Anggraini (2011), motivasi belajar mahasiswa adalah sebagai suatu keadaan dalam diri mahasiswa yang mendorong dan mengarahkan perilakunya pada tujuan yang ingin dicapainya dalam mengikuti pendidikan tinggi. Idealnya tujuan mahasiswa dalam mengikuti pendidikan tinggi adalah untuk menguasai bidang ilmu yang dipelajarinya. Dengan demikian, mahasiswa terdorong untuk menguasai bahan pembelajaran yang diperolehnya dengan baik dan bukan hanya untuk sekedar lulus meski dengan nilai yang sangat baik sekalipun.

Pelaksanaan PKBM dapat menjadi salah satu media yang sangat strategis dalam meningkatkan prestasi belajar mahasiswa. Kegiatan PKBM merupakan sarana yang handal untuk meningkatkan kemampuan pengetahuan (knowledge), ketarampilan (skill) dan sikap (attitude) mahasiswa selama mengikuti pendidikan jarak jauh di UT (Sinaga dan Hardiati, 2001). Pengetahuan dan keterampilan mahasiswa tentang sistem pembelajaran jarak jauh harus dimiliki sedini mungkin, sejak pertama masuk UT. Dengan demikian diharapkan dapat menimbulkan sikap positif dalam diri mahasiswa sehingga termotivasi untuk belajar. Motivasi belajar tersebut menjadi bekal penting bagi mahasiswa dalam proses belajar, dikarenakan proses belajar membutuhkan interaksi dan partisipasi aktif dari mahasiswa (Dedi S., $d k k, 2016)$.

Penelitian ini dilakukan untuk melihat pengaruh PKBM terhadap motivasi belajar pada mahasiswa penerima beasiswa Bidikmisi di Unit Program Belajar Jarak Jauh Universitas Terbuka (UPBJJ-UT) Ternate. Hal ini penting mengingat mahasiswa penerima beasiswa bidikmis UT adalah mereka yang baru tamat SLTA dan kuliah di UT. Secara otomatis konsep belajar mandiri dalam sistem belajar jarak jauh masih asing bagi mereka, karena selama di bangku SLTA peran guru dalam proses belajar masih dominan. Sementara dalam konsep belajar mandiri menurut Long (1989) lebih ditujukan kepada orang dewasa.

Kondisi Maluku Utara yang secara geografis merupakan kepulauan dengan keterbatasan infrastruktur di bidang teknologi informasi/teknologi komunikasi, maka pemahaman masyarakat terhadap sistem belajar jarak jauh, sebagaimana yang diselenggarakan oleh UT, masih sangat awam bagi mereka. Berdasarkan hasil penelitian Anfas dan Zainuddin (2018) yang dilakukan di SLTA yang ada di Maluku Utara, dari 420 responden yang mengemukakan ingin melanjutkan kuliah jika tamat SLTA, data menunjukkan bahwa hanya $108(23,43 \%)$ yang pernah mendengar UT dan hanya 3 siswa $(1,23 \%)$ yang menyatakan tertarik kuliah di UT. Penyebabnya 
tidak lain adalah persepsi mereka yang masih menganggap kuliah itu harus secara tatap muka.

Sementara itu, dari data mahasiswa beasiswa Bidikmisi dan CSR UT di UPBJJ-UT Ternate dari tahun 2013-2016 (dimana mahasiswanya merupakan mahasiswa fresh graduate sebanyak 175 mahasiswa), yang mampu melanjutkan studi di UT hingga masa registrasi 2016.1 hanya sebanyak 101 mahasiswa, diakibatkan nilai yang diperoleh kurang baik, sehingga beasiswa terhenti dan mereka pun memilih mundur/tidak kuliah lagi (Sudarwo $d k k, 2018$ ).

Hasil penelitian-penelitian tersebut (Anfas \& Zainudin,2018; Sudarwo, $d k k$, 2018) menunjukkan pentingnya mengedukasi masyarakat berkaitan dengan penyelenggaran sistem pendidikan jarak jauh. Termasuk pemberian pelatihan bagi calon mahasiswa baru UT, agar memperoleh wawasan tentang sistem pendidikan jarak jauh sehingga dapat memberikan motivasi belajar mereka. Penelitian tentang pengaruh PKBM terhadap motivasi belajar mahasiswa UT belum pernah dilakukan, sehingga sejauhmana pengaruh PKBM terhadap motivasi mahasiswa belum diketahui. Namun, setidaknya dari beberapa hasil penelitian, seperti yang dilakukan Nugraha (2011), Utami, dkk (2014), Lutfianawati, dkk (2014) dan Sandayanti, dkk (2018) menunjukkan bahwa dari berbagai jenis pelatihan yang mereka teliti yang ada kaitannya dengan peningkatan keterampilan belajar siswa, memiliki pengaruh terhadap motivasi belajar siswa.

\section{METODE PENELITIAN}

Penelitian ini menggunakan metode penelitian kualitatif yang mengukur pengaruh Pelatihan Keterampilan Belajar Mandiri (PKBM) sebagai variabel independen $(X)$ terhadap motivasi belajar mahasiswa sebagai variabel Dependen (Y). Populasi penelitian adalah mahasiswa baru UPBJJ-UT Ternate yang menerima beasiswa Bidikmisi di masa registrasi 2019.2 sebanyak 20 mahasiswa. Mengingat jumlah mahasiswa kurang dari 100 maka seluruh populasi dijadikan sebagai sampel penelitian (Sugiyono, 2013).

Data penelitian dikumpulkan melalui kuesioner yang dibagikan kepada seluruh responden. Kuesioner disajikan dalam bentuk skala likert untuk semua variabel, baik pada variabel pelatihan $(\mathrm{X})$ maupun variabel motivasi belajar $(\mathrm{Y})$. Pada variabel PKBM $(X)$ terdapat 10 pertanyaan berkaitan dengan manfaat PKBM, kesesuaian materi dan peningkatan wawasan dan pengetahuan tentang sistem belajar jarak jauh, serta peningkatan keterampilan dalam mengakses layanan belajar online di UT. Sedangkan untuk variabel Morivasi Belajar (Y) terdiri dari 17 pertanyaan terdiri dari pertanyaan berkaitan kepercayaan diri dalam belajar, ketertarikan dalam mengikuti tutorial, semangat mengerjakan tugas, dan keaktifan dalam tutorial (berdiskusi maupun bertanya). Seluruh pertanyaan, baik pada vaiabel $X$ maupun $Y$ ada lima alternatif jawaban yang diberikan pada tiap pertanyaan yaitu sangat setuju (SS), setuju (S), agak setuju (R), tidak setuju (TS), dan sangat tidak setuju (STS).

Sebelum digunakan, kuesioner terlebih dahulu diuji kepada non-responden dan diuji validitasnya sehingga dapat mengukur tingkat akurasi instrumen yang digunakan. Setelah itu, uji reliabilitas dilakukan untuk menentukan keakuratan data. Sebelum menguji hipotesis menggunakan analisis regresi, data yang diperoleh 
terlebih dahulu diuji menggunakan uji normalitas untuk menentukan normalitas data dan korelasinya, sebagai syarat untuk analisis regresi. Sedangkan uji multikolinieritas, tidak dilakukan karena dalam penelitian ini hanya terdiri dari satu variabel independen $(X)$. Tahap akhir analisis adalah uji hipotesis penelitian menggunakan analisis regresi berganda untuk mengetahui pengaruh masingmasing variabel independen $(X)$ terhadap variabel dependen $(Y)$ (Sugiyono, 2013).

\section{TEMUAN DAN PEMBAHASAN}

\section{Hasil Uji Validitas}

Teknik pengujian yang sering digunakan para peneliti untuk uji validitas adalah menggunakan korelasi Bivariate Pearson (Produk Momen Pearson). Analisis ini dilakukan dengan cara mengkorelasikan masing-masing skor item dengan skor total. Jika rhitung $\geq$ rtabel (uji 2 sisi dengan sig. 0,05, df = N-2) maka instrumen atau item-item pertanyaan berkorelasi signifikan terhadap skor total (dinyatakan valid).

Uji validitas item pertanyaan pada Variabel Pelatihan Keterampilan Belajar Mandiri $(X)$ dan Variabel Motivasi Belajar Mahasiswa $(Y)$ memiliki nilai korelasi rhitung $\geq 0,423$ (rtabel, $d f=20-2=2$ ). Sehingga dapat dikatakan bahwa item pertanyaan Variabel Keterampilan Belajar Mandiri $(X)$ valid dan dapat digunakan untuk mengukur variabel yang diteliti. Terkecuali pada item pertanyaan nomor 9 tidak valid, karena nilai korelasi rhitung $<0,423$ sehingga item pertanyaan tersebut dikeluarkan dari uji validitas karena tidak dapat digunakan untuk mengukur Variabel Pelatihan Keterampilan Belajar Mandiri (X).

Hasil uji validitas pada item pertanyaan Variabel Motivasi Belajar Mahasiswa (Y) juga dinyatakan valid dan dapat digunakan untuk mengukur variabel yang diteliti. Terkecuali pada item pertanyaan nomor 2, 3, 5, 8, 12, 15, 16, dan 17 tidak valid, karena nilai korelasi rhitung $<0,423$ sehingga item pertanyaan tersebut dikeluarkan dari uji validitas karena tidak dapat digunakan untuk mengukur Variabel Motivasi Belajar Mahasiswa (Y).

\section{Hasil Uji Reliabilitas}

Pada uji reliabilitas dilihat apakah suatu kuesioner tepat, konsisten, dan dapat dipercaya untuk digunakan sebagai alat pengumpul data. Uji reliabilitas dalam penelitian ini menggunakan koefisien alpha (a) Cronbach. Suatu instrumen penelitian dikatakan reliabel apabila memiliki koefisien alpha (a) $>0,60$. Berdasarkan hasil uji reliabilitas, didapatkan hasil seperti terlihat pada Tabel 1.

Tabel 1. Hasil Uji Reliabilitas

\begin{tabular}{lccc}
\hline \multicolumn{1}{c}{ Variabel } & $\begin{array}{c}\text { koefisien alpha } \\
(\alpha) \text { Cronbach }\end{array}$ & Keterangan & $\begin{array}{c}\text { Tingkat } \\
\text { Realibilitas }\end{array}$ \\
\hline $\begin{array}{l}\text { Pelatihan Keterampilan Belajar } \\
\text { Mandiri }(\mathrm{X})\end{array}$ & 0,759 & Reliabel & Kuat \\
Motivasi Belajar Mahasiswa $(\mathrm{Y})$ & 0,830 & Reliabel & Sangat Kuat \\
\hline
\end{tabular}


Dari hasil uji reliabilitas seperti terdapat pada Tabel 1 diperoleh hasil koefisien alpha (a) Cronbach variabel Pelatihan Keterampilan Belajar Mandiri (X) sebesar $0,759>0,60$. Sehingga dikatakan reliabel yang artinya bahwa 9 item pertanyaan dalam kuisoner penelitian tersebut mempunyai tingkat keandalan kuat. Sedangkan hasil koefisien alpha (a) Cronbach variabel Motivasi Belajar Mahasiswa (Y) sebesar 0,830 $>0,60$. Sehingga dikatakan reliabel, yang artinya bahwa 9 item pertanyaan dalam kuisoner penelitian tersebut mempunyai tingkat keandalan yang sangat kuat.

\section{Hasil Uji Normalitas}

Tabel 2. Hasil Uji Normalitas

One-Sample Kolmogorov-Smirnov Test

\begin{tabular}{llcc}
\hline & & PKBJJ & Motivasi Belajar \\
\hline$N$ & & 22 & 22 \\
Normal Parameters ${ }^{a, b}$ & Mean & 41,27 & 60,45 \\
& Std. Deviation & 3,210 & 5,087 \\
& Absolute & 0,124 & 0,127 \\
Most Extreme Differences & Positive & 0,124 & 0,127 \\
& Negative & $-0,120$ & $-0,100$ \\
Kolmogorov-Smirnov Z & & 0,582 & 0,593 \\
Asymp. Sig. (2-tailed) & & 0,887 & 0,873 \\
\hline
\end{tabular}

a. Test distribution is Normal.

b. Calculated from data.

Dari Tabel 2 terlihat bahwa data untuk variabel Pelatihan Keterampilan Belajar Mandiri $(X)$ diperoleh Asymp. Sig. $(0,887)>0,05$ dan variabel Motivasi Belajar Mahasiswa $(Y)$ diperoleh Asymp. Sig. $(0,873)>0,05$, sehingga dapat disimpulkan bahwa data yang digunakan pada variabel tersebut berdistribusi secara normal.

\section{Hasil Regresi}

Dari hasil analisis regresi, dapat lihat pada output coefficient dan disajikan pada Tabel 3.

Tabel 3. Hasil Uji Coefficients

Coefficients $^{a}$

\begin{tabular}{|c|c|c|c|c|c|c|}
\hline \multirow[t]{2}{*}{ Model } & & \multicolumn{2}{|c|}{$\begin{array}{l}\text { Unstandardized } \\
\text { Coeficients }\end{array}$} & \multirow{2}{*}{$\begin{array}{c}\text { Standardized } \\
\text { Coefficients } \\
\text { Beta }\end{array}$} & \multirow[t]{2}{*}{$t$} & \multirow[t]{2}{*}{ Sig. } \\
\hline & & $B$ & Std. Error & & & \\
\hline & (Constant) & 5.274 & 7.877 & & .670 & .511 \\
\hline & PKBM & 1.337 & .190 & .844 & 7.026 & .000 \\
\hline
\end{tabular}

a. Dependent Variable: MotivasiBelajarMahasiswa 
Berdasarkan Tabel 3 persamaan regresi yang menjelaskan pengaruh Pelatihan Keterampilan Belajar Mandiri $(X)$ terhadap Motivasi Belajar Mahasiswa $(Y)$ adalah $Y=a+b X=5.274+1.337 X$

Nilai konstanta (a) sebesar 5.274 dan koefisien regresi variabel sarana belajar b1 sebesar 1.337 yang menyatakan bahwa setiap perubahan Pelatihan Keterampilan Mandiri sebesar satu satuan, maka akan meningkatkan Motivasi Belajar Mahasiswa sebesar 1,337 satuan.

Tabel 4. Hasil Uji Koefisien Determinan

Model Summary

\begin{tabular}{ccccc}
\hline Model & $\boldsymbol{R}$ & $\boldsymbol{R}$ Square & Adjusted $\boldsymbol{R}$ Square & Std. Error of the Estimate \\
\hline 1 & $.844^{\mathrm{a}}$ & .712 & .697 & 2.799
\end{tabular}

a. Predictors: (Constant), Pelatihan Keterampilan Belajar Jarak Jauh

Berdasarkan data pada Tabel 4 koefisien determinasi R2 ( $R$ Square) sebesar 0,712 . Hal ini menunjukkan bahwa presentase sumbangan pengaruh variabel Pelatihan Keterampilan Belajar Mandiri $(X)$ terhadap variabel Motivasi Belajar Mahasiswa (Y) sebesar (71,20\%). Sedangkan sisanya sebesar 28,80\% dipengaruhi atau dijelaskan oleh variabel lain yang tidak dimasukkan dalam model penelitian ini.

Selanjutnya dari hasil uji Koefisien Regresi (uji Anova) diperoleh nilai Fhitung $49.361>$ Ftabel 4.30 atau nilai Sig $(0.000)<(0,05)$, sehingga dapat disimpulkan bahwa ada pengaruh signifikan pelatihan keterampilan belajar mandiri (PKBM) terhadap tingkat Motivasi Belajar Mahasiswa.

Tabel 5. Uji Koefisien Regresi

\begin{tabular}{|c|c|c|c|c|c|c|}
\hline \multicolumn{7}{|c|}{ ANOVAa } \\
\hline & & $\begin{array}{l}\text { Sum of } \\
\text { Squares }\end{array}$ & $d f$ & Mean Square & $F$ & Sig. \\
\hline \multirow{3}{*}{1} & Regression & 386.750 & 1 & 386.750 & 49.361 & $.000 \mathrm{~b}$ \\
\hline & Residual & 156.704 & 20 & 7.835 & & \\
\hline & Total & 543.455 & 21 & & & \\
\hline
\end{tabular}

a. Dependent Variable: Motivasi Belajar Mahasiswa

b. Predictors: (Constant), Pelatihan Keterampilan Belajar Jarak Jauh

Tingginya kontribusi PKBM terhadap peningkatan motivasi belajar mahasiswa baru UT $(71,20 \%)$, menunjukkan bahwa pelaksanaan PKBM sangat menolong mahasiswa selama mereka dalam proses belajar di UT. Dengan meningkatnya motivasi belajar tersebut maka diharapkan dapat meningkatkan prestasi belajar mereka.

Sebagaimana hasil penelitian Mulyono dkk (2007) yang dilakukannya pada mahasiswa Keperawatan di Universitas Jenderal Soedirman, menunjukkan hasil bahwa pelatihan gaya belajar terhadap mahasiswa berpengaruh terhadap Indeks 
Prestasi Akademiknya. Dimana tiap responden yang telah memperoleh pelatihan gaya belajar, memiliki kenaikan Indeks Prestasinya yakni rata-rata 0,58.

Penelitian Utami, $d k k$ (2014), menunjukkan bahwa siswa yang mendapatkan pelatihan tentang cara belajar akan mendapatkan beberapa manfaat selama mengikuti pelatihan, seperti lebih termotivasi menjadi lebih baik, lebih semangat untuk menggapai cita-cita, mampu berpikir positif, mengetahui cara mengubah kesulitan/tantangan menjadi sebuah kesempatan untuk mengubah diri (bukan sebagai halangan), tidak mudah putus asa, memiliki rasa peduli terhadap teman, serta lebih fokus kepada hal mana yang harus dikerjakan/ diselesaikan. Demikian pula dikemukakan oleh Djamarah (2011), bahwa seorang siswa yang telah termotivasi, akan terdorong untuk selalu ingin maju dalam belajar, memiliki kesadaran untuk melakukan aktivitas belajar, menjadi gemar belajar dan menjadikan belajar sebagai kebutuhannya. Maka, hal inipun tentunya dirasakan oleh mahasiswa UT setelah mendapatkan PKBM, mereka akan lebih mengenal sistem belajar jarak jauh, lebih yakin mudah mempelajari modul UT, semangat mengikuti tutorial, lebih aktif di dalam tutorial, dan lebih tertantang untuk dapat menyelesaikan tugas tutorial.

Untuk itu PKBM sangat penting diselenggarakan sehingga setiap mahasiswa baru UT, dapat meningkatkan pengetahuannya tentang sistem belajar jarak jauh serta meningkatkan keterampilannya dalam mengakses layanan belajar, terutama yang berbasis online di UT. Mengingat banyaknya mahasiswa UT yang tersebar dari Sabang sampai Meroke, penyelenggaraan PKBM ini bukanlah perkara mudah, namun cukup memakan waktu, tenaga dan biaya. Sebagaimana dikemukakan oleh Handoko (2000), bahwa meskipun program pelatihan pada suatu organisasi/institusi akan memakan waktu dan dana yang tidak sedikit, namun hampir semua organisasi melaksanakannya, dan menganggap bahwa biaya-biaya untuk berbagai program tersebut sebagai investasi dalam sumber daya manusia. Dengan kata lain, dengan adanya PKBM, maka UT akan mampu menciptkan mahasiswa yang menguasa konsep sistem belajar jauh serta memiliki prestasi akademik sesuai dengan disiplin ilmunya masing-masing.

\section{SIMPULAN}

PKBM memiliki pengaruh yang signifikan terhadap motivasi belajar mahasiswa baru di UT. Terutama bagi mahasiswa yang masih fresh graduate dan masih asing tentang konsep belajar mandiri dalam sistem belajar jarak jauh. Berdasarkan hasil penelitian ini, maka peneliti mengusulkan agar UT harus terus dapat meningkatkan standar PKBM sehingga semakin baik dan dapat membantu mahasiswa baru UT dalam menjalani proses belajarnya selama di UT.

\section{REFERENSI}

Aisyiyah, Siti. (2013). Pengaruh Kondisi Lingkungan Dan Motivasi Terhadap Kemandirian Belajar Mahasiswa Politeknik Negeri Jember. Jurnal IImiah INOVASI, Vol.13 No.1, p38-47. DOI: https://doi.org/10.25047/jii.v13i1.

Anfas \& Zainuddin. (2018). Implementasi SWOT Pada Institusi Pendidikan Dalam Meningkatkan Angka Partisipasi Kasar. Jurnal Organisasi dan Manajemen, Vol. 14, No. 1, p82-93. 
Anggraini, I. S. (2011). Motivasi Belajar Dan Faktor-Faktor Yang Berpengaruh: Sebuah Kajian Pada Interaksi Pembelajaran Mahasiswa. Premiere Educandum: Jurnal Pendidikan Dasar dan Pembelajaran. Vol. 1, No. 2, p100-109, DOI: http://doi.org/10.25273/ pe.v1i02.39.

Belawati, T. (2002). Perkembangan pemikiran tentang pendidikan terbuka dan jarak jauh. Jakarta: Universitas Terbuka.

Bolliger, D.U. \& Martindale, T. (2004). Determining Student Satisfaction in Online Courses. International Journal on E-Learning, Vol. 3, No. 1, p61-67.

Dedi S., dkk. (2016). Pengaruh Motivasi Belajar, Gaya Belajar, Dan Kemandirian Belajar Terhadap Hasil Belajar Mahasiswa S1 PGSD Masukan Sarjana di UPBJJ-UT Bandung. EduHumaniora: Jurnal Pendidikan Dasar, Vol. 8, No. 2, p163-177, DOI: https://doi.org/10.17509/eh.v8i2.5139.

Djamarah, S. B., (2011). Psikologi Belajar. Jakarta : PT. Rineka Cipta.

Handoko, T.H. (2000). Manajemen Personalia dan Sumber Daya Manusia. Yogyakarta: BPFE.

Hasibuan, H. Malayu S.P. (2005). Manajemen Sumber Daya Manusia. Jakarta: Bumi Aksara.

Long, H.B. (1989). Self-directed learning: Emerging theory \& practice. USA: Oklahoma ResearchCenter.

Lutfianawati, D., dkk. (2014). Pengaruh Pelatihan Goal Setting terhadap Motivasi Belajar bahasa Inggris Siswa. Jurnal Intervensi Psikologi, Vol. 6, No. 1, p125-138.

Moore, M.G., \& Kearsley, G. (1996). Distance education: A systems view. Belmont, CA: Wadsworth Publishing.

Mulyono, W.A dkk. (2007). Pengaruh Pelatihan Gaya Belajar Terhadap Peningkatan Indeks Prestasi Mahasiswa. Jurnal Keperawatan Soedirman (The Soedirman Journal of Nursing), Vol. 2, No.3, p134-140, DOI: 10.20884/1.jks.2007.2.3.129.

Neal, Ed (1999). Distance education: Prospects and Problems. KAPPA PHI Journal, Vol. 79, Issu 1, p41-43.

Nugraha, R.A. (2011). Pengaruh Pelatihan Kecerdasan Adversitas Terhadap Motivasi Berprestasi Pada Siswa Kelas X di SMA Negeri 8 Surakarta. Skripsi, Universitas Sebelas Maret Surakarta.

Prayekti, dkk. (2016). Pengaruh Kemandirian Belajar Terhadap Hasil Belajar Mahasiswa Bidik Misi Masa Registrasi 2016.1. Prosiding Temu IImiah Nasional Guru (TING) VIII, 26 November 2016, p143-154.

Sandayanti, V., dkk. (2018). Pengaruh Pelatihan Aku Dan Targetku Terhadap Motivasi Belajar Matematika Pada Siswa SMP "X". ANFUSINA: Journal of Psychology, Vol. 1, No. 1, p.45-60, doi://dx.doi.org/10.24042/ajp.v1i1.3637.

Sinaga, A. M. \& Hardiati W.K, Sri. (2001). Pemberdayaan Sumber Daya Manusia. Bahan Ajaran Diklatpim Tingkat III. Jakarta: Lembaga Administrasi Negara (LAN) R.I.

Sudarwo, R., Yusuf \& Anfas. (2018). Pengaruh Sarana Belajar Dan Motivasi Belajar Terhadap Kemandirian Belajar Mahasiswa (Studi Empiris Pada Mahasiswa Beasiswa Bidikmisi UPBJJ-UT Ternate). Jurnal Pendidikan, Vol. 19, No. 2, p68-83. 
Sugiyono (2013). Motode Penelitian Pendidikan (Pendekatan Kuantitatif, kualitatif dan R\&D). Bandung: Alfabeta.

Sylvana, Andy \& Alwi, M. (2016). Pengaruh Motivasi Belajar Dan Kemandirian Belajar Terhadap Prestasi Belajar Mahasiswa Penerima Bidikmisi Universitas Terbuka Studi Pada Unit Program Belajar Jarak Jauh-UT Makassar. Prosiding Seminar Nasional FEKON-UT, p162-171.

Universitas Terbuka. (2012). Panduan Belajar di Universitas Terbuka. Tangerang Selatan.

Universitas Terbuka. (2018). Pedoman Pelaksanaan Kegiatan Edukasi Kesiapan Belajar Mahasiswa (EKBM) Universitas Terbuka. Tangerang Selatan.

Ural, Ozana. (2007). Attidues of Graduate Students Toward Distance Education, Educational Technologies And Independent Learning. Turkish Online Journal of Distance Education, Vol. 8, No.4, p34-43.

Utami, S. dkk (2014). Pengaruh Pelatihan Adversity Quotient Untuk Meningkatkan Motivasi Belajar Siswa Sekolah Menengah Pertama. Jurnal Intervensi Psikologi, Vol. 6, No. 1, p131-149. 